\title{
Managing Divergence in EFL Doctoral Education of a Chinese University
}

\author{
Hongbing Peng ${ }^{1}$ \\ ${ }^{1}$ College of Foreign Studies, Jinan University, Guangzhou, Guangdong, 510632, China \\ Correspondence: Hongbing Peng, College of Foreign Studies, Jinan University, Guangzhou, Guangdong, 510632, \\ China.
}

Received: May 13, 2016 Accepted: May 30, 2016 Online Published: June 14, 2016

doi:10.11114/smc.v4i2.1605

URL: http://dx.doi.org/10.11114/smc.v4i2.1605

\begin{abstract}
The present interview study was a part of a larger investigation which was chiefly made in 2010. Its purpose is to examine and manage the divergence perceived in the supervisory relationship by doctoral students and their supervisors in terms of the aims and academic views of the doctoral program in EFL research supervision of a Chinese university. Discourse System (DS) proposed by Scollon and Scollon (2000) is applied to guide the analysis of the study as an interpretive framework. 11 doctorates and 12 doctoral supervisors participated in the research. The results showed that the program was felt demanding by the students due to a number of factors. The students were particularly expected to have "revolution in one's soul" experience which they did not hope for out of realistic considerations. The results also indicated that academic views were in conflict because of differences in research aims, areas and interests between the two sides. The study suggests that the supervisory relationship is hierarchical as a result of lack of mutual negotiation and concerns of group harmony. The form of professional tutoring is proposed to manage divergence in the EFL doctoral education in the end.
\end{abstract}

Keywords: supervision problems, solutions, divergence, EFL doctoral education, professional tutoring

\section{Introduction}

Much literature has examined the common problems related to research students, supervisors, graduate education and graduate supervisory system in the Chinese EFL research supervision, and offered major corresponding suggestions. The major problems shared by the research students contain difficulties in assessing literature, lack of critical thinking abilities, confusing logical relations in thesis writing, weak independent thinking ability, not studying hard, poor autonomous learning ability and limited knowledge (Dai, 2000; Dai, 2009; Sun, 2008; Wang, 2010; Wen et al, 2006; Wen, 2008; Zhang, 2005). The main problems with the supervisors comprise a lack of research competence, supervisory competence and academic integrity (Zhang \& Yang, 2009). The primary problems concerning graduate education are found in objectives, course study, dissertation writing, research quality, teaching methods, teaching content, research ethics, research methodology, and curriculum design (Dai, 2009; Sun, 2008; Wang, 2009a; Wen, 2002; Zhang \& Yang, 2009). The chief problems with respect to graduate supervisory system cover objectives, model, entrance examination, comprehensive qualities, exit system, academic conferences, and evaluation system (Dai, 2009; Sun, 2008; Wen, 2002; Zhang \& Yang, 2009; Zhu, 2005). The suggestions are thus given in terms of graduate education (Sun, 2008; Wang, 2008a; Wang, 2009a, 2009b; Wen, 2002; Wen et al, 2006; Zhu, 2003; Zhu, 2005) and administrative system (Wen et al, 2006; Zhang \& Yang, 2009).

The most recent research pertaining to EFL supervisory relationship in China (Peng, 2016) reported the perceptions graduate students and supervisors had on the effectiveness of Chinese EFL academic socialization based on in-depth interviews from the angle of discourse system (DS hereafter) proposed by Scollon and Scollon (2000). The results found that both supervisors and students had certain complaints with the research supervision, including inadequate supervision, unstructured tutorial and unmanaged time in the academic process. The study suggests that the non-bureaucratic administrative system which serves as the greatest limiting factor hinders the professional development of individuals and adversely affects the effectiveness of academic socialization. The system which is demonstrated by no division of supervision power, informal and relaxed supervision and an absence of detailed and explicitly stated rules and regulations fails to regulate and restrict supervision behavior and supervision practice properly. It is proposed that a pro-supervising research community should be designed to enable its students to produce quality research outcome and its supervisors to concentrate on academic duties only (Kennedy, 1997). 
The above study poses the following questions for more study:

1. Are there other dissatisfactions in the relationship?

2. How a pro-supervising research community is designed?

In this paper, the researcher will further the inquiry of complaints which might affect the effective Chinese EFL supervisory relationship. The study aims to investigate the divergence perceived in the relationship and propose the form of professional tutoring which is likely to support a pro-supervising Chinese EFL research community of practice (Lave \& Wenger, 1991). DS, as an interpretive framework, will also be applied to guide the analysis of the present interview study (For details, see Peng, 2016).

\section{Literature Review}

A significant body of literature has discussed the problems between graduate students and their supervisors preceding this study.

\subsection{Problems for Research Students and Roles of Supervisors}

Among the students' criticism of supervisors (Delamont, 1983; McAleese \& Welsh, 1983; Rudd, 1985; Brown \& Atkinson, 1988), it was said that supervisors sometimes met students infrequently, did not tell students how to phase their work, gave too little direction and practical help, took too little interest in the student or in the students' research topic, and retained students' written work for an inordinate length of time. Some supervisors were held to lack relevant research experience, skills and knowledge of the students' topic and others were unapproachable or physically absent from the department. There was a neglect of students for long periods of weeks, months, even years, in the humanities and the social sciences and exploitation in joint ownership of doctoral research between supervisors and students in the science (Philips \& Pugh, 2010).

The most common problems identified with research students (Delamont, 1983; Brown \& Atkinsons, 1988) were as follows: poor planning and management of a project, isolation, writing up, management, inadequate supervision and personal problems outside the research (Rudd, 1985); students who may be at risk of failing may be identified by such warning indications as postponing supervision, making frequent changes in the topic or method, procrastinating writing or making excuses for unfinished work, filling time with other things, resisting advice or criticism and blaming others (the supervisors?) for shortcomings (Brown \& Atkinsons, 1988); lack of methodological skills, isolation or loneliness and lack of time were the most common difficulties (Delamont, 1983).

Recent issues shared by supervisors and supervisees include isolation, conflict, non-compliance, plagiarism, time, language, writing, scrutiny, transfer, progress, judgment, distance teaching, management, culture, funding, appeal, stability, ownership, availability, health, direction, contract, priority, write-up, viva preparation, identity, alleged fraud, collaboration and procedure (Eley \& Jennings, 2005).

\subsection{Major Solutions}

Considering a large array of issues encountered by supervisors and students in the prior literature, a host of effective coping strategies has been in place to manage a variety of problems.

First, selected possible preventions and resolutions taken against the recent supervision issues contain ensuring that research students experience a congenial research culture; communication between students and supervisors; induction event/program clearly outlining the responsibilities of both parties at the outset; encouragement; formalization of supervisory procedures; regular supervisory meetings; record keeping of supervisory meetings; agreed upon timetable at the outset for time management; sensitivity to cultural differences; awareness training for supervisors and students regarding regulations, policies and procedures; improvement of student selection; availability of computer software to check plagiarism in electronic documents for supervisors; making clear the nature of contract between supervisors and students; change of supervisors; termination of registration; complaints and appeals (Eley \& Jennings, 2005).

Second, a host of strategies are proposed for students and supervisors to manage their relationship. For students, knowledge of the university system and the nature of $\mathrm{PhD}$ study, research skills, skills in research management, communication, networking and teamwork, career management and personal effectiveness, and group supports are needed; they are advised to seek help from the relevant school committee or other responsible officials from being victimized; for supervisors, teaching credit or resource should be allocated for doctoral supervision to avoid a perfunctory way of treating students; the number of students should be limited, and craft of research supervision is needed (Philips \& Pugh, 2010). All these measures can "help maintain a healthy and productive relationship that fosters intellectual growth."

What's important, a contractual approach is also suggested to solve some problems supervisors encounter with regard to difficult students (Hockey, 1996). The notion is conceptualized as a written contract or agreement negotiated, agreed upon 
and signed between the supervisor and student before the parties concerned enter into supervisory relationship. In this way, legal compliance can be induced by enforcing the reciprocal rights and responsibilities. Samples of written agreement in terms of research can be seen in the handbooks of graduate schools in some universities (Queen's University, 2007; Skarakis-Doyle, 2008; The University of Western Ontario, 2008; University of British Columbia, 2011; ABO Akademi, 2012).

\subsection{Divergence}

Discrepancies shared by supervisors and supervisees were different aims and expectations held by each and resulting mismatches and problems.

\subsubsection{Incongruent Academic Aims}

According to Philips and Pugh (2010), there were many reasons why students decided to work towards a PhD: the wish at the beginning to make a significant contribution to the chosen field, enhance career opportunities and future earning capacity through possession of the $\mathrm{PhD}$ degree, not to feel guilty at accepting a title they had not received in a workplace such as laboratory or hospital department, communications with their medical colleagues may be easier if they too had the title, not to feel alone in their academic group without a title and succumbed to feelings of peer pressure in order to conform, and simply taking up the offer of a studentship as a form of employment and without having any real career aims.

In a similar way, supervisors undertook supervision with different aims in mind (Phillips \& Pugh, 2010): wishing to add to their reputation for having a large number of successful research students of high caliber, believing that postgraduates should be encouraged to become autonomous researchers (for arts and social science professors), believing they should be encouraged to become extremely efficient research assistants (for science and technology professors), aiming to become eligible for a Nobel Prize or other senior honor, wishing to get the work done as speedily and efficiently as possible, producing more and better researchers, and offering a service of supervision to research students in the same way as they offered a service of teaching to undergraduate students.

Considering the cases of different aims held by supervisees and supervisors, a number of measures can be taken to manage them (Phillips, \& Pugh, 2010). First, the aim of PhD study should be simple to students. It was determination and application, rather than brilliance, which were needed. Second, four things that students could first do were: discover which approach a prospective supervisor favored in order to evaluate the implications for what would be expected of them, understand what was on offer, talk to other research students in the department about their experience of supervision, and introduce into the preliminary discussions with any potential supervisor an exploration of their preferred way of working with their students. Finally, the tension between the boundaries of the research project and the time available to complete it should be continually reviewed and adjusted by the student and the supervisors.

\subsubsection{Mismatched Academic Expectations}

Relevant research reveals what students expect of their supervisors. Supervisors are expected to have regular supervision, to read students' work well in advance, to be available when needed, to be friendly, open and supportive, to be constructively critical, to have a good knowledge of the research area, to have structured tutorial, to offer guidance in research topic and direction, to have sufficient interest in students' research, to put more information in the students' path, and help them get a good job in the end (James \& Baldwin, 1999; University of Pennsylvania, 2006; Philips \& Pugh, 2010; Acadia University, Mount Saint Vincent University \& St. Francis Xavier University, 2011; The London School of Economics and Political Science, 2011-2012; University of British Columbia, 2011).

Related research also shows what supervisors expect of their student. Students are expected to take initiative and be independent in doing research, to work hard on their research projects, to meet their supervisors regularly, and to be conscientious in meeting their responsibilities as graduate students (University of Pennsylvania, 2006; Philips \& Pugh, 2010; Acadia University, Mount Saint Vincent University \& St. Francis Xavier University, 2011; LSE, 2011-2012; UBC, 2011).

The literature implies that students and supervisors must understand the importance of acquiring the inside information of what each expects of the other, so that they would be in a better position to develop the necessary skills, reduce communication barriers and sustain the relationship for mutual benefit.

\subsection{Summary}

In a word, the above literature has demonstrated the common problems encountered by research students and supervisors. Divergence in aims and expectations may bring about extra problems in research areas and interests for supervisory relationship. Nonetheless, research shows that effective mentoring relationship can be achieved by a supplementary mutually agreed-upon written contractual solution to a variety of supervisory troubles. The desirable relationship can be 
further achieved by enforcing the respective explicitly stated rights and responsibilities highly related to all sides involved in addition to the existing educational and administrative measures. In this way, interests of all parties are protected.

\section{Methods}

U/C (note 1), a nationally renowned university of foreign studies located in one capital city of south China, was chosen as the research site for the present study. Eleven doctoral students and twelve doctoral supervisors of U/C took part in the investigation. The instrument used in this research for all student and supervisor informants included an interview guide, an informed consent and a copy of interview questions. All were in Chinese. In-depth interview, the major investigation method for supervisees and supervisors, formally began in June 2010 and lasted until December 2010. Most of the interviews were conducted once, with a few three times, followed up by triangulations in the form of emails now and then from 2011 to 2014. The total interview time for the students and the supervisors reached over 19 hours and more than 22 hours respectively. Free nodes were raised into tree nodes driven by the DS framework. Then tree nodes were integrated into categories. The data was then integrated and re-categorized based on the principles of grounded theory (Charmaz, 2006). Emerging and recurring patterns and abstract themes resulted from data analysis. A major category was decided after its theme was repeated by over five informants. Finally, the Chinese text was then translated into English in verbatim and presented in the text by following the conventions summarized by Richards (2003) (For details of the methods, see Peng, 2016).

\section{Results}

The results that are to be presented below are a part of the larger investigation the researcher completed for her $\mathrm{PhD}$ dissertation in 2014. The account which is practically a dataset provided by 11 doctoral students and 12 graduate supervisors is a series of subcategories of all commonly shared perceptions by them. Each subcategory is followed by description and supported by the data of both groups. Although many doctoral students said they got good supervisors in their supervision, so did the supervisors of their students, both groups pointed out there were still some cases when they showed dissatisfaction with the other side as far as supervision was concerned. The following presentation of the research data is arranged under the headings of demanding $\mathrm{PhD}$ program and conflicting academic views.

\subsection{Demanding PhD Program}

The most popular complaint agreed upon by almost all $\mathrm{PhD}$ informants was the demanding nature of the program, which made students have a hard time in their studies. Supervisee A summarized:

Since the research topics begin to be approved, namely, the second semester of the second year, the supervisees are generally under tremendous pressure. Until the third and fourth year, they dare not talk about this issue, that is to say, the pressure is so great that they try to avoid it, and the insiders are especially very sensitive to this issue. To an outsider, doing a $\mathrm{PhD}$ is just like doing undergraduate study, but to those who have experienced this process, they believe it is very tough. This is for sure, and this is absolute. (Quoted verbatim from \#101)

The pressure felt by the supervisees can be observed in doing their PhD study. At the start, some doctoral students would climb the famous mountain nearby in the late afternoon as their favorite pastime, and sing songs to have some relaxation after a day's intensive study in their dorms, especially male students. But in the second and the third year, "they couldn't sing out loud with a heavy heart", one supervisee said. Several factors were attributed to the demanding nature of the program. First, it was closely related to its glorious tradition, namely, the number one position it assumed within the discipline in the nation. Supervisors were very hard with their students in order to maintain its national reputation, though they would not make things difficult for students on purpose. For example, "training an expert" rather than an average doctoral student was targeted in one case of supervising $\mathrm{PhD}$ students.

Second, originality was required in theoretical aspect of the dissertation writing, which was thought to be very tough to achieve for a doctoral student as supervisee $\mathrm{G}$ explained:

This is very, very hard for a $\mathrm{PhD}$ candidate given the limited time for study. The first difficulty is that supervisees must have a comprehensive knowledge and deep thinking of one's research field; the second difficulty is that supervisees must construct one's own theoretical system by breaking through predecessor's thoughts. (\#107C)

Third, it was hard for most students to graduate within the required three years of the study because of considerable time spent on the topic selection, research methodology study, theoretical framework application, and data collection. Supervisee $\mathrm{C}$ said:

The topic chosen should be the newest in the world; research methodology must be suitable, then your data, your theoretical framework, your interpretations of data, must all match. If all is to be met, I believe three years is not enough to finish $\mathrm{PhD}$ education, that's for sure, I should add, three years, that is for experienced students, because data collection is very time-consuming and pressure we are under is tremendous at the same time. The conflict is 
inherent or intrinsic, regardless of excellent supervisors or quality supervisees... I'm a perfectionist who would like to continue the cooperation as well. Otherwise, the friction is even greater, I'm afraid. (\#103)

Supervisee $\mathrm{F}$ also agreed three years was not enough for the situation in $\mathrm{U} / \mathrm{C}$, in his opinion, four or four and a half year was appropriate for full-time students. But supervisors couldn't understand, in their opinion, students' progress was too slow. Supervisee C added:

Supervisors think the student should have graduated, but standing from students' position, they need time, and inspiration whatever. In fact, in the middle, both supervisors and supervisees feel helpless, at that time, creativity is needed. However, creativity is accompanied by inspiration, and creativity is not something you can have when needed... the length of time is uncertain. (\#103)

Students' difficulty could even be exacerbated because of the unsound knowledge foundation before their admission. Supervisee J said:

My undergraduate and graduate studies did not help much with my $\mathrm{PhD}$ research area. I studied literature as an undergraduate, but linguistics during postgraduate study. So I had great trouble studying translation during doctoral days. Relatively speaking, U/C was strict with students, so, to a person without much foundation like me, I had to spend more time and efforts than others. (\#110B)

Confronted with the above difficulties, some supervisees could understand, as supervisee $G$ explained:

It was very hard at that time. But now when I look back, it was helpful to me. Until now, on the basis of the dissertation, I succeeded in applying for one research project with the Ministry of Education, and published seven related journal articles, including five articles of second national class, one article in Foreign Languages and one article in Language Sciences. This means that in the long run it's right for supervisors to be hard with their supervisees. I feel I should follow the suit with my own students later. (\#107B)

Those who were motivated to learn more during the candidature just came to terms with supervisors and their requirements. However, the other supervisees, who had a different idea of the nature of a dissertation, strongly resented the tough work. Supervisee F commented:

Many [supervisees] have questioned [the definition of] the dissertation, the demands cannot be too high, and it can only be an ordinary one. Why? The dissertation is something of an apprenticeship. It is a learning process, and it is not an embodiment of one's ultimate academic level. (\#106A)

This point resonated with supervisee $\mathrm{K}$, who said:

Academic demands must be high, and scholarly research must be rigorous, but there is a matter of degree sometimes, that is to say, supervisors can be hard in normal times, so students can learn more. For example, our Daodu (tutorial) was very rigorous, from which I benefitted a lot. But in times of dissertation writing, or presenting the research results, if a supervisor's demand is too high, students are unable to graduate within four or five years, then they will be under tremendous pressure. (\#111A)

One student informant had a different notion of doing a PhD. In his view, $\mathrm{PhD}$ study did not mean finishing a dissertation only and no laboring for good later. One could read more books and do research projects afterwards. Pursuit of a high quality dissertation sometimes may dissipate one's academic passion and entail such a long time as long as six years, or even seven years before, during which one has to pay dearly. A popular saying was jokingly coined for a time to summarize the impact of $\mathrm{PhD}$ study life upon a person by the time of completion, which goes as "liang yan wu shen" (spiritless eyes), "si zhi wu li" (weak limbs), "gong neng sang shi" (functionless organs) and "qing jia dang chan" (bankrupt homes). Some supervisees did go bankrupt because of PhD study, as they didn't have a Danwei (work unit) themselves. Some of their lives were even supported by their wives' meager income, which couldn't last as long as five or six years of study. "Students are social people, they have to survive", supervisee E said.

To them, the demands were too ideal to be realized. They complained the standards aimed to be in line with the international ones, but they were not in line with the reality. For instance, the school library information conditions were not adequate. One supervisee told the researcher informally, students were unable to have access to foreign databases like ScienceDirect or WileyBlackwell in recent years because they were too expensive for the school's budget.

In addition, students felt even unbalanced if they were unable to graduate on time and had to extend their study to further years when the graduation standards of $\mathrm{U} / \mathrm{C}$ were compared with those of other universities of the same nature which did not follow the same steps as U/C. Instead, they took a different path, such as making money by running MA or PhD classes. Supervisee F commented resentfully:

This high demand doesn't work at all. The psychological contrast is felt sharply when it is well known that every student can graduate on time within three years in one university, regardless of their poorly-written dissertations. 
There is no need for one to labor so hard! I dare to say the high demand is absolutely not positive but negative to some extent ... I felt very lost, lost in those years... (\#106A)

So the student-supervisor relationship in U/C was, comparatively speaking, believed to be more strained rather than relaxed than other universities where students could graduate within three years, with the above factors taken into consideration. This was evidenced by the remarks of supervisee A:

As far as I know, at the very beginning, they show great trust in their supervisors, but after a period of time, especially after topic selection, due to differences or strict demands or whatever reasons, they have complaints towards their supervisors more or less, even resentments, that is to say, 'I'm very tired of doing $\mathrm{PhD}$, why not let me graduate earlier?' Such cases exist, even the words, "I hate him" were said... Those who are driven by degree only want to graduate early. To them, the sooner they can graduate, the better it is. (\#101)

In a word, students have different opinions of the demanding nature of the PhD program. Nevertheless, the supervisors had their own considerations. Supervisor 10 said:

Doing a PhD [for liberal arts students] is a process of transformation of soul. It is a process of destroying, smashing, and overturning the previous existing mindset and reestablishing a new way of thinking on the basis of the ruins. It is a process of "ling hun shen chu nao ge ming" (having revolution in one's soul), in the words of the "Cultural Revolution". It is "fan tian fu di de bian hua" (an earth-shattering change). (\#210)

In his belief, doing a PhD was supposed to be "an agonizing process, which required students' reflections," in a similar manner as their western counterparts who just left or quitted because they could not stand the process or could not do it because of the demands. First, in this process, students needed an insight to identify the research field accurately, namely, what was to be researched or what was to be solved after a plenty of analysis of the prior research. Second, the elements and their inner relations involved in the research problem should be analyzed. Third, a correct approach should be established to solve the problem. Finally, they should stand the test of being questioned from all sides. The ideal student should possess a silver tongue, power of observation and integration, and strong critical thinking abilities after such academic socialization. He was worth 100 postgraduates. He could do many things others could not. He could do the most advanced things. He was not a simple carrier who spent much time doing nothing of value. Hard as the process was, these attributes should be the goals supervisors strove for. However, supervisees couldn't appreciate and accept his beliefs, so he felt very frustrated. He explained:

Some doctoral candidates can't accept [the beliefs]. If you ask him to do something, then he will have a conflict with you. For instance, his supervisor asks him to make revision, and he does not want to do this. A supervisor asks him to do that, and he does not want to do it either. He is not used to it, and he is unwilling to accept it. Some PhD students are in their 30s and 40s when they come to study. Their mindset is already out there. Doctoral supervisors actually do something, which is very painful not only to themselves, but also to their students, as it is equivalent to reforming a person, from his soul, not from his body, and it is a transformation of the soul, so it is very challenging, not an easy thing. (\#210)

Therefore, he felt grieved when seeing some students who came to U/C finish one topic, and graduate with a degree without learning much. In his conviction, if the student was given another topic, he would not know how to do it, just like before. If the student was asked to do it independently, without the guidance of teachers, he could not do it either. So the supervisor regarded his supervision as a disappointment:

But now, I think my teaching for these ten years is a failure, because I see students don't want to have such thinking, they don't want it as long as they can finish dissertation writing. Sometimes I feel very sad, sometimes I'm suspicious of myself, why I have spent so much time supervising them? They don't want to accept, and they seem they can't wait for graduation, so I feel very upset. I remember I said it in one opening ceremony of graduate students: it was hard to express my feelings when I saw those students graduate without learning anything. (\#210)

As a result, it was tough for him to admit students again because the latter could not understand his beliefs and his effort. He continued:

Why this is so? Such a good opportunity, I often tell my doctoral students this is the last time in your life that there is someone who pays so much attention to your writing. After graduation, who wants to read your dissertation? Who wants to? Who will so care about it by reading word for word, no one, and this is the last chance in your life. It is basically just like this, unless you contribute your articles to western journals, [their] editors will sit down and read it word by word, and that is looking up to you, the person who analyzes your article looks up to you. Ordinary people will throw it into trash can after having two looks. These things happen often, don't they? But few students can understand our good intentions, our pain. I even did not want to admit students two years ago, and I thought I had spent so much time on it, which could have been used to read books myself, supervision is very hard, because 
students cannot understand your supervision methods. They always think why you are "na me kou" (so detail-oriented), why you are so "tiao san jian si" (picky), but actually our goal is to develop their subtlety, their intellectual rigor, but this stuff, these things, but they cannot realize, they don't want to try, they don't want to experience such things, feeling these is very painful, so I say, it is all right, it is all right, we just do our own things, don't spend time on those who don't want to learn! ... Therefore, clash is inevitable, and it is inevitable, because in the student's system, his expectations are not so high. (\#210)

In this case, he had to compromise in order to handle the clash, but conditionally in decision-making, and unconditionally in doing research. Considering the real life challenges faced by students and consequences of possible disasters, the clash must be handled properly. He would be generally very critical in his comments of research, but in the end, in decision making, he would take the consequence into account. He would "shou xia liu qing" (show mercy) for the dissertations which could not have been passed, that is to say, his scolding was fierce, but he would not beat them, namely, "dao zi zui, dou fu xin" (knifelike mouth, doufulike heart).

\subsection{Conflicting Academic Views}

Given the contrasting aims held by both groups towards the doctoral program, it is not too hard to realize that certain conflicts are inherent in the system. Supervisors and supervisees may have different views in the research area and interests.

This [conflict in views] will exist forever: it exists now, existed in the past, and will exist in the future. First, perspectives and positions held by supervisors and supervisees towards issues are different. It is inevitable that some supervisees think the project is of value while supervisors think the opposite. Additionally, their knowledge background and personal interest vary. Supervisors think the project is of significance, while supervisees who have their own interest would like to choose a more meaningful topic. At that time, conflict is unavoidable. (\#103)

Some student informants said they were empowered to make their own decision with regard to thesis topic selection and writing as long as they could justify it and persuade their own supervisors. The latter would not force their students to follow their ideas, but they would offer some suggestions, help think about the problems from students' positions and have a quality check of their drafts and finished copies in the end. But on the other hand, there existed contrary views over topic selection, methods of doing research, research interest, ideas, and style of supervision. The conflicting views were finally resolved mainly by the students' compromise in diverse ways.

In the first place, supervisors who had projects needed students to do data collection and analysis, but students who were motivated only by getting a degree quickly didn't want to accept the supervisors' recommendations. That is to say, those students wanted to graduate early, get a degree and get a job as early as possible. Learning more for doing projects would take them more time.

In the second place, even if students would like to do projects for supervisors motivated by the same purpose, there were still discrepancies concerning means and ends of academic issues, in other words, some concrete methods or notions varied, such as specific measures in collecting data.

Moreover, supervisees hoped their supervisors could allow them to choose a project they were interested in and could help their future development, but might end up with something which was against their wishes. In this case, they were finally persuaded by supervisors' positions. Their supervisors allowed his students to do the project, but would say they didn't have confidence, or say this seemed not good to them, or say students could choose something else. So finally students would more or less return to the place where supervisor was in. "After all, as a Chinese popular saying goes, "ge bo ning bu guo da tui" (arms are not stronger than legs), one student explained. But most importantly, the projects students came up with would not normally work if supervisors did think there was something wrong with it. Anyway, students were still limited in terms of accumulation, competence and vision academically.

Disagreements may occur in supervision style as well. For instance, one supervisor preferred a progress report from his student every month, while the supervisee preferred to hand in the complete version of dissertation in the end. Then the supervisor felt unhappy and gave pressure to his student. In this case, the supervisee would speed up writing so as not to keep his supervisor waiting too long.

When students' ideas were denied by supervisors, which were not hoped for or unacceptable to them, their self-confidence was hardly hit and self-esteem was hurt. This usually happened after admission when supervisors' philosophies were not fully understood. Some supervisees quickly adjusted themselves by thinking hard while others felt sad or wronged at the beginning but felt nothing later. In one case, one supervisee's topic was sensed a bit ambitious, and there was anger in his supervisor's voice, so the student had to change his attitude and speech quickly.

Finally, when it came to the unavoidable argument, suspension of hostilities was deemed as necessary for face concerns rather than direct confrontation. In one case, a student had different views in some places of his dissertation with his 
supervisor. Both argued, emotionally charged. The student turned in the revised draft to his supervisor after he calmed down for a period of time, considering his face. Supervisee E explained:

When it came to the supervisors' problems, we all communicated in private, not in front of many people, by this means, we tried to avoid...because in some cases face concerns would be involved, in this situation, generally, in private, namely, going to office or without the presence of others. (\#105A)

In this case, no arguing was regarded as effective as put by supervisee $\mathrm{C}$ :

If there is such a conflict, it is better for both to negotiate for some time, in my understanding. I had a peer who was faced with a conflict like this. My advice was: don't talk with your supervisor face to face, first think it over, and send him emails when he has calmed down. Then you two talk again. Give both some space for thinking, talk after thinking. Don't argue when he denies your idea. That doesn't help. Later my peer followed my advice and handled it well. (\#103)

In his opinion, if conflict did occur, it must be handled with care. Otherwise, indifference or hatred might arise between the two parties. Students should learn how to resolve or dissolve it, though they could not control what supervisors were thinking about. Supervisee F also supported no arguing with supervisors. He explained, "You cannot argue with supervisors basically. We do not argue basically. Just accept what supervisor has said. My junior peers sometimes argued with my supervisor, he would compromise. As to differences in ideas and topic selection, just accept what you can accept. There is no need for arguing. Chinese culture does not provide such a possibility." Supervisee $\mathrm{G}$ also agreed by saying that "when our opinions are in conflict, generally I compromise first (because of minding supervisor's face). After a period of time, when he has calmed down, I submitted the revision points, and they were passed successfully."

The student informants' views were confirmed in the interviews with the supervisor informants. One supervisor verified the above contradictions between supervisors and students in terms of topic selections. He explained the relationship may be strained for some pairs, since students thought the topics were reasonable while supervisors thought just the opposite. But, he insisted that, if supervisors were right, or raised different opinions from a better or higher position which students couldn't think through, they shouldn't be angry. They could talk about with their peers or other supervisors about this to see if their supervisors were right or not. Many times, students were wrong, but they couldn't realize why, wondering why their idea was denied after so much work. It was not so easily denied. Supervisors were those who helped students to get degrees as early as possible, and they were not their enemies. Students should always think that their supervisors were thinking for them, by putting on a different pair of shoes. In this way, there would be no contradictions.

The supervisors confirmed the above discrepancies by mentioning difficulties of supervising doctoral students in revision. For instance, their supervisees were reluctant to make more revisions for their dissertations due to external factors, like graduation deadline or finding jobs or life difficulties. Supervisor 12 said:

Generally we asked students to revise power points from three to five times and dissertations five to eight times, in fact, students would normally "da zhe kou" (make discounts or do less), to the last moment, students finally said, they didn't have such a patience, they would get a degree first, or said, you see the time was pressing, revision can be made after the viva, anyway, there were very few, very few who could follow what we wanted, that is to say, finally, they all would make some discounts...you know, they said, this was much better than others, you were very strict, you see what $\mathrm{xxx}^{\prime}$ ' dissertation was like, they could pass. There are some interferences and we have no way. So it is very hard to make them strictly follow our requirements, it is hard to be realized. So I just said, it was okay if you could reach the middle, our requirements were very high, and you were still good if the level was lowered a bit. (\#212)

In the students' mind, their supervisors made a hard time for them on purpose. They thought highly of their own writings, but didn't realize their problems. They ignored their own problems their supervisors had pointed out. Some even said bad words against their supervisors behind their backs. Supervisor 12 added:

They said their supervisors did not understand their writings, they said I did not know anything, said I was lazy to supervise, very tough, said I must do what, I must do what. This also existed, and then I needed to guide him, persuade him, guide him kindly. (\#212)

The supervisors in U/C often repeated a Chinese saying that "hao wen zhang shi gai chu lai de" (a good article was a product of much revision). It was their firm belief that revision was essential for quality, so there should be enough time set aside for revision between the first draft and the final draft. The student informants could understand their teachers' good intentions: more revision meant better writing. But they did not want to do so at times as a result of job-hunting, family burden, or practical reasons. Supervisee H's explanations were insightful: endless revision made students very tired. They were too tired of revision or too tortured to have another look at their own writing. Sometimes, time left for revision was not sufficient for students. Accordingly, conflict arose. 


\section{Discussions}

\subsection{Not well-communicated Academic Aims and Expectations}

It is evident that there is difference towards the aims of $\mathrm{PhD}$ program. The supervisees prefer a less-demanding doctoral program given the realities. However, the supervisors expect a demanding one which their students can follow, even though the former have already agreed to meet the latter halfway.

First, the program is felt to be demanding due to the fact that the supervisors attempt to maintain its traditional leading academic position in the whole nation and insist on theoretical originality in doing research. Doctoral students are expected to experience what is called "revolution in one's soul", namely, to learn something real as well, which their supervisors have personally experienced in their PhD study. In their view, this type of academic socialization is real training, which will benefit students' future career. Some students try to live up to the high criteria from career development perspective despite their weak knowledge foundation and lengthy study time, while the others resent it because of their loose standards held towards the nature of the doctoral program considering the realities of obtaining degrees, finding jobs and relaxed standards in other universities. The realistic expectation of getting dissertation done as early as possible is not in agreement with the idealistic expectation of "transformation in soul" which takes time. Thus, the students' resentments of having the doctoral program were harbored against their supervisors while the latter's enthusiasm of fostering real scholars is dampened to a considerable extent.

What's more, the academic aims and expectations are not well communicated between students and supervisors. The demanding nature of doctoral program is not well communicated to the students by the supervisors and the school before the program commences in any formal and specific way, so students are unable to get well prepared for the upcoming challenges after admission when high academic obligations are placed upon the students. Even worse, there is no system for students to exit despite the supervisors' dissatisfaction. Thus, ensuing crashes are inevitable, resulting in hatred of students and diminished zeal of supervisors, which might be detrimental to the relationship.

\subsection{Group Harmony vs. Individual Welfare}

It is obvious from the above that group harmony counts more than individual welfare when academic views are in conflict. Academic views claimed by students and supervisors differ in terms of topic selection, writing, research methods, research objectives and supervision style as a result of opposing knowledge background, research interest, research perspectives, and realistic considerations. The contradictions are chiefly resolved by students' ultimate self-adjustment, compromise and no argument due to harmony concerns. The supervisors resort to compromise for their discontentment out of realistic considerations at the moment of important decision-making as well.

Besides, the normal academic differences in research are indirectly addressed by students' compromise at the expense of truth inquiry, for fear of offending supervisors directly. They are also indirectly addressed by supervisors' compromise for fear of students' unpleasant consequences. There seems to lack a healthy critical culture in the community, which is taken as a norm in the western academia. Individual creativity is not developed in this way.

\subsection{Hierarchical Relationship vs. Egalitarian Relationship}

The supervisory relationship is ratified rather than negotiated. The academic obligations cannot be well negotiated. The needs of the students and supervisors are not essentially considered. As a result, lack of negotiation of mutual aims and expectations after admission may directly explain confrontations. Moreover, judging from the ways of reacting to the demanding program and conflicting views, it is found that the means the students resort to are indirect response to dissatisfaction for fear of offense and hostility. This suggests they are in a powerless position vis-à-vis their supervisors. They dare not express their true minds about the other party directly. The possible reasons are that supervisors have the critical power to determine life and death of students' fate, namely, whether students can graduate or not is closely correlated with their supervisors. The best strategy is to tolerate until graduation. All these are signs of supervisors' hierarchy in interpersonal relations.

The community relationship is hierarchical in the power relation as well. The outspoken frankness, as reported in the above interview responses, contain a fair number of strong expressions of emotions, and usually critical emotions from both groups. They may be embodiments of the hierarchy in the whole community of practice. Supervisors and supervisees lack complaints and appeals procedure which include informal, administrative and formal channels to resolve their complaints if supervision troubles crop up. They also lack a sense of security even if given a chance to vent out their grievances as their respective rights and responsibilities are not well-protected by the school regulations. The researcher is trusted by the supervisors with outspokenness because of an insider. What's more, the frankness revealed to the researcher happens after students' graduation and as a result of researcher's long-term friendship with them. This implies that both supervisees and supervisors are in a powerless position vis-à-vis the community in terms of power relationship. Both are actually sufferers of community hierarchy which has its origins in Confucianism which 
dominates their cultural values and behavior in and out of schools for a long time. The hierarchy which gives rise to non-bureaucratic administrative system yields a variety of supervision problems. The problems are caused by indirect confrontation and non-legal relations which depict a harmony-oriented and non-contractual Chinese research community of practice.

According to Peng (2015), with the development of the times, especially during the transformational era now in China, the traditional supervisor/supervisee relationship, with supervisors as absolute authority, has been challenged due to academic and non-academic factors. The "paternalistic leadership style" incidents draw attention to the problematic relationship in the academic community. Things remain fundamentally unchanged regardless of much discussion. The situation should be addressed by resorting ways to design a pro-supervising research community. The community is supposed to support egalitarian relationship between the two sides until the latter becomes something of a well-informed junior peer.

\section{Conclusion}

To sum up, the divergence in the aims of $\mathrm{PhD}$ programs and subsequent research views should be managed. It is observable that there is an entire absence of the professional form of tutoring in the EFL doctoral education, in which "contract is emphasized and trust is in the background" (Hockey, 1996). One strategy appears to be needed to remedy the situation along with the existing moral, educational and administrative measures. As Hockey suggests (1996), a written contract should be negotiated between supervisor and student to formalize relationship and handle supervision issue. The contract includes a set of detailed and explicitly-stated reciprocal obligations and rights agreed upon by mutual agreement, strictly observed by both parties, and by which mutual interests can be protected. Thus, the professional relationship can be developed. The future study can be conducted by better reconciliation of varied responses within both groups of supervisors and doctoral students and between these groups. This is hard to be implemented in the current study due to the Confucian culture in the community.

\section{Acknowledgements}

I would like to express my heartfelt gratitude towards all anonymous research informants from U/C, without whose continued support, cooperation and encouragement, this research would have been impossible. I am very grateful for the anonymous reviewer whose constructive suggestions make the final form of the article possible.

\section{References}

Abo Akademi University. (2012). Supervision and Study Agreement. Retrieved September 7, 2012 from web.abo.fi/lc/forskarskolan/Blanketter/en-02-avtal.pdf

Acadia University, Mount Saint Vincent University \& St. Francis Xavier University. (2011). Handbook on Graduate Supervision: Nurturing and Managing the Supervisor and Doctoral Student Relationship. Retrieved December 21, 2011 from http://www.educationphd.ns.ca/

Brown, G., \& Atkins, M. (1988). Effective Teaching in Higher Education. London: Methuen.

Charmaz, K. (2006). Constructing Grounded Theory: A Practical Guide Through Qualitative Analysis. Sage Publications Ltd.

Dai, W. D. (2000). A talk about PhD supervision. Foreign Language Teaching and Research, 5(5), 385-386.

Dai, W. H. (2009). EFL disciplinary construction and graduate education. Foreign Language World, 6, 2-9.

Delamont, S. (1983). 'A Necessary Isolation? A report on students' attitude to their higher degree research', in J. Eggleston \& S. Delamont (eds.) Supervision of Students for Research Degrees with Special Reference to Educational Studies, Reading: BERA.

Eley, A. R., \& Jennings, R. (2005). Effective Postgraduate Supervision: Improving the Student-Supervisor Relationship. Open University Press.

Hockey, J. (1996). A Contractual solution to problems in the supervision of PhD supervisor's role. Studies in Higher Education, 21(3), 359-371.

James, R., \& Baldwin, G. (1999). Eleven Practices of Effective Postgraduate Supervisors. The Center for the Study of Higher Education and the School of Graduate Studies, the University of Melbourne.

Kennedy, D. (1997). Academic Duty. Cambridge: Harvard University Press.

Lave, J., \& Wenger, E. (1991). Situated Learning: Legitimate Peripheral Participation. Cambridge, UK: Cambridge University Press.

McAleese, R., \& Welsh, J. (1983). "Supervision of Postgraduate Research Students: a review of recent developments", 
in J. Eggleston \& S. Delamont (eds.) Supervision of Students for Research Degrees with Special Reference to Educational Studies. Reading: BERA.

Office of the Provost, University of Pennsylvania. (2006). Graduate Supervision: Guidelines for Students, Faculty, and Administrators at the University of Pennsylvania.

Peng, H. B. (2015). Assessing the quality of research supervision in mainland Chinese higher education. Quality in Higher Education, 21(1), 89-100. http://dx.doi.org/10.1080/13538322.2015.1049441.

Peng, H. B. (2016). Perceptions of graduate students and supervisors on the effectiveness of Chinese EFL academic socialization: interview results. Journal of Education and Training Studies, 4(6), 104-114. http://dx.doi.org/10.11114/jets.v4i6.1360.

Philips, E. M., \& Pugh, D. S. (2010). How to get a PhD: A Handbook for Students and Their Supervisors (5 ${ }^{\text {th }}$ edition). Open University Press

Richards, K. (2003). Qualitative Inquiry in TESOL. New York: Palgrave Macmillan. http://dx.doi.org/10.1057/9780230505056

Rudd, E. (1985). A New Look at Postgraduate Failure. Guildford: NFER-Nelson.

School of Graduate Studies and Research, Queen's University. (2007). FANALSGS Student-Supervisor Guide handbook.

Scollon, R., \& Scollon, S. (2000). Intercultural Communication: A Discourse Approach. Beijing: Foreign Language Teaching and Research Press/ Blackwell Publishers Limited.

Skarakis-Doyle. (2008). Western Guide to Graduate Supervision. The University of Western Ontario Teaching Support Center.

Sun, Y. H. (2008). Viewpoints on reforming EFL graduate supervision model. China Higher Education, 13 \&14, $47-49$.

The London School of Economics and Political Science. (2011-2012). Handbook for Research Degree Students. Retrieved January 27, 2013 from www2.lse.ac.uk/europeanInstitute/home.aspx.

University of British Columbia. (2011). Handbook of Graduate Supervision. Retrieved December 20, 2011 from www. Grad. ubc. ca

Wang, X. M. (2008a). EFL postgraduate evaluation and academic competence development. Journal of Liberation Army College of Foreign Studies, 31(3), 63-68.

Wang, X. M. (2009a). Curriculum design and academic competence of EFL postgraduates. Foreign Language World, 1, 44-50.

Wang, X. M. (2009b). Analyzing the connotations and functions of EFL graduate supervisors from the perspective of academic competence development. Foreign Language World, 6, 43-49.

Wang, X. M. (2010). Reflections on Chinese EFL MA graduate education from the perspective of needs analysis of academic competence. Foreign Language World, 5, 67-74.

Wen, Q. F. (2002). Major problems and measures in MA graduate education. Degree and Graduate Education, 5, 21-24.

Wen, Q. F. (2008). Discussion on developing EFL postgraduates' advanced level thinking competence. Degree and Graduate Education, 10, 29-34.

Wen, Q. F., Ding, Y. R., Chen, X. R., \& Wang, W. Y. (2006). Building a learning community to improve the overall quality of postgraduate programs on applied linguistics for English majors. Chinese Foreign Language, 3(2), 11-13. http://dx.doi.org/10.13564/j.cnki.issn.1672-9382.2006.02.007

Western Graduate Studies. (2008). Template- Letter of Understanding. The University of Western Ontario.

Zhang, D. L. (2005). Exploration of reforming EFL graduate supervision model. Foreign Languages of China, 2(4), 8-11. http://dx.doi.org/10.13564/j. cnki .issn.1672 -9382.2005.04.001

Zhang, S. J., \& Yang, Z. (2009). Education of EFL PhD program: problems and measures. Foreign Languages of China, $1,4-8$.

Zhu, X. L. (2005). Multi-dimensional explorations on EFL graduate education. Foreign Languages, 1, 77.

Zhu, Y. (2003). Research paper writing and research competence of graduate students. Foreign Language and Teaching, 7, 25-27. 


\section{Notes}

Note 1. A pseudonym is used for the university under the study of the researcher in order to mask its true identity for the purpose of confidentiality and anonymity.

Appendix: Selected interview questions:

1. How do you select the research topic? (For students)

2. How do you argue? How to compromise in the case of disagreement? (For students and supervisors)

3. What are supervision criteria? in terms of quality, quantity and originality? (For students and supervisors)

This work is licensed under a Creative Commons Attribution 3.0 License. 